\title{
On the neural networks of empathy: A principal component analysis of an $\mathrm{fMRI}$ study Jason S Nomi11,2, Dag Scherfeld1', Skara Friederichs1, Ralf Schäfer', Matthias Franz ${ }^{3}$, Hans-Jörg Wittsack ${ }^{4}$, Nina P Azari ${ }^{2}$, John Missimer ${ }^{5}$ and Rüdiger J Seitz*1,6,7
}

\begin{abstract}
Address: ${ }^{1}$ Department of Neurology, University Hospital Düsseldorf, Moorenstrasse 5, 40225, Düsseldorf, Germany, ${ }^{2}$ Department of Psychology, University of Hawaii at Hilo, College of Arts and Sciences, 200 W. Kawili Street, Hilo, Hawaii 96720-4091, USA, ${ }^{3}$ Clinical Institute of Psychosomatic Medicine and Psychotherapy, University Hospital Düsseldorf, Moorenstrasse 5, 40225 Düsseldorf, Germany, ${ }^{4}$ Institute of Diagnostic Radiology, University Hospital Düsseldorf, Moorenstrasse 5, 40225 Düsseldorf, Germany, 5 Paul Scherrer Institute, 5232 Villigen, Switzerland, ${ }^{6}$ Biomedical Research Centre, Heinrich-Heine-University Düsseldorf, Moorenstrasse 5, 40225 Düsseldorf, Germany and ${ }^{7}$ Brain Imaging Centre West, 52407 Jülich, Germany

Email: Jason S Nomi - jason.nomi@colostate.edu; Dag Scherfeld - scherfeld@uni-duesseldorf.de; Skara Friederichs - kleinskara@web.de; Ralf Schäfer - schaefra@uni-duesseldorf.de; Matthias Franz - matthias.franz@uni-duesseldorf.de; Hans-Jörg Wittsack - wittsack@uniduesseldorf.de; Nina P Azari - azari@hawaii.edu; John Missimer - john.missimer@psi.ch; Rüdiger J Seitz* - seitz@neurologie.uni-duesseldorf.de

* Corresponding author
\end{abstract}

Published: 17 September 2008

Behavioral and Brain Functions 2008, 4:4I doi:I0.1|86/I744-908I-4-4I
Received: 7 April 2008

Accepted: 17 September 2008

This article is available from: http://www.behavioralandbrainfunctions.com/content/4/I/4 I

(c) 2008 Nomi et al; licensee BioMed Central Ltd.

This is an Open Access article distributed under the terms of the Creative Commons Attribution License (http://creativecommons.org/licenses/by/2.0), which permits unrestricted use, distribution, and reproduction in any medium, provided the original work is properly cited.

\begin{abstract}
Background: Human emotional expressions serve an important communicatory role allowing the rapid transmission of valence information among individuals. We aimed at exploring the neural networks mediating the recognition of and empathy with human facial expressions of emotion.

Methods: A principal component analysis was applied to event-related functional magnetic imaging (fMRI) data of I 4 right-handed healthy volunteers ( $29+/-6$ years). During scanning, subjects viewed happy, sad and neutral face expressions in the following conditions: emotion recognition, empathizing with emotion, and a control condition of simple object detection. Functionally relevant principal components (PCs) were identified by planned comparisons at an alpha level of $p<0.001$.

Results: Four PCs revealed significant differences in variance patterns of the conditions, thereby revealing distinct neural networks: mediating facial identification (PC I), identification of an expressed emotion (PC 2), attention to an expressed emotion (PC I 2), and sense of an emotional state (PC 27).
\end{abstract}

Conclusion: Our findings further the notion that the appraisal of human facial expressions involves multiple neural circuits that process highly differentiated cognitive aspects of emotion.

\section{Introduction}

Human emotional facial expressions contain information which is essential for social interaction and communication [1-3]. Social interaction and communication depend on correctly recognizing and reacting to rapid fluctuations in the emotional states of others $[4,5]$. This capability may have played a key role in our ability to survive and evolve [6]. 
In the research field of psychological childhood development the competence to detect, share, and utilise cognitive patterns and emotional states of the other was conceptualized as mentalizing [7]. The important aspect is that the emotion expressed in someone else's face is not only detected but also valuated from the subjective perspective of the observer. In fact, the appraisal of and the resonance with an emotion observed in somebody else is central to the concept of empathy [8-11].

We can acquire two important sources of information upon perceiving a face: the identification and emotional expression of the individual [12-15]. Support for distinct networks of facial identification and emotional recognition have been provided by studies of those with traumatic brain injuries [16], electroencephalograph (EEG) studies $[17,18]$, magnetoencephalography (MEG) studies [19], and also by studies examining the influence of emotional expression on familiar faces [20]. EEG studies have also hypothesized that these two networks operate in a parallel system of recognition in which emotional effects and structural facial features are simultaneously identified through distinct neural networks $[8,9]$.

When inferring the emotional expression of another, we are automatically compelled to compare our assessment of their emotional state with our own. A key component of perspective taking and emphatic experiences is the ability to compare the emotional state of oneself with another [8-11,21]. However, a distinct separation between first and third-person experiences is necessary $[8,22]$. People are normally able to correctly attribute emotional states and actions to the proper individual, whether they are our own or someone else's [23]. Confusing our emotional state with another would vitiate the function of empathy and cause unnecessary emotional distress and anxiety [24].

Therefore, a number of distinct psychological states functioning in concert may be necessary in order for a proper emphatic experience to occur [25]. They may include the evaluation of emotion of the self, evaluation of another's emotion, comparing those emotions, and anticipating and reacting to our own or another's emotion, among others. In accord with this line of thought, Decety and Jackson [26] have proposed three major functional components of emphatic experiences. First, the actions of another person automatically enact a psychological state in oneself which mirror those actions and create a representative state which incorporates the perceptions of both the self and another. Secondly, there must be a distinct separation between the perception of the self and the other person. Finally, the ability to cognitively assume the perception of another person while being aware of self/ other separation is important.
Each psychological state may be associated with distinct neural networks containing cortical areas which interact within and across neutral networks. The interactions foster an exponentially complex environment within which the processes driving emphatic responses occur. While the processes have been explored to some extent, much work is needed to reveal the precise nature of the complex interaction among the constituents of empathy.

Accordingly, empathy has been suggested to involve distinct, distributed neural networks. Such distributed networks demand the application of a network analysis, which subjects voxels of the image matrix to a multivariate rather than a univariate analysis. This feature allows a network analysis to overcome two significant limitations of univariate analyses that are based on categorical comparisons: they are unable to distinguish regional networks because the constituent voxels may not all change at the defined level of significance and may also show areas of activation which are unrelated to the phenomenon being studied [27].

The network analysis applied to the blood oxygen level dependent (BOLD) signals in this functional magnetic resonance imaging (fMRI) study is a principal component analysis (PCA), which decomposes the image matrix into statistically uncorrelated components. Each component represents a distinct neural network, and the extreme voxel values of a component image, its nodes. Thus, the component images map the functional connectivity of constituent regions activated during neural stimulation. Previous studies have proposed and verified the hypothesis of functional connectivity in regions-of-interest [28] and voxel-based analyses [29-31]. In contrast to regions that show enhanced metabolic or blood flow levels correlated with mental states [31], the networks deduced by PCA incorporate no a priori assumptions regarding the neural stimulation.

Virtually unexplored until now, the neural networks associated with recognizing and empathizing with human facial expressions of emotions are here described using PCA.

We attempt to elucidate the functional neural networks central to the processes of recognizing and empathizing with emotional facial stimuli recorded in fMRI acquisitions of healthy subjects.

Statistical testing identified four principal components (PC) as relevant neural networks. The correlation of the subjects' scores of emotional experience with the PC's further supported their functional relevance. Our analysis shows the coordinated action of brain areas involved in the processing of visual perception and emotional 
appraisal underlying the facial expressions of human emotions. These regions, including pre-frontal control areas and occipital visual processing areas presumably constitute nodes of the networks implicated in appraising other people's emotion in their facial expressions.

\section{Methods}

\section{Subjects}

Fourteen healthy, right-handed subjects $(28.6+/-5.5$ years; 7 men, 7 women) participated in this study. The subjects had normal or corrected to normal vision. Righthandedness was assessed using the Oldfield's questionnaire [32]. In addition, the subjects' emotional competence was tested with the German, 20-item version of the Toronto Alexithymia Scale (TAS-20) [33-35]. None of the participating subjects were classified as alexithymic (mean TAS-20 sum score 34.14+/- 6.26, range 23). Subjects were also evaluated with the Beck Depression Inventory [36] and the scales of emotional experience (SEE) [37].

\section{Visual stimuli}

From photographs of facial affect [38], we selected for presentation those with happy, sad and neutral facial expressions found to be correctly identified in more than 90 percent of raters; 14 happy, 14 sad, and 14 neutral faces were used. Only faces which had been found to be correctly identified in more than 90 percent of raters [38] were used to ensure that the subjects internally generated the corresponding emotion. This corresponded to a similar approach of a recent study [39]. As control stimuli we produced a number of scrambled images from these photographs equal to the number of intact faces. All images were digitized and controlled for luminescence.

\section{Experimental task design}

Faces were presented for durations ranging between 300 and $500 \mathrm{~ms}$, since this short presentation time is sufficient for conscious visual perception avoiding habituation [40]. The presentation time of the faces was jittered to enhance the detection of the stimulation-related BOLD activity changes in this event-related fMRI study. Thereafter,

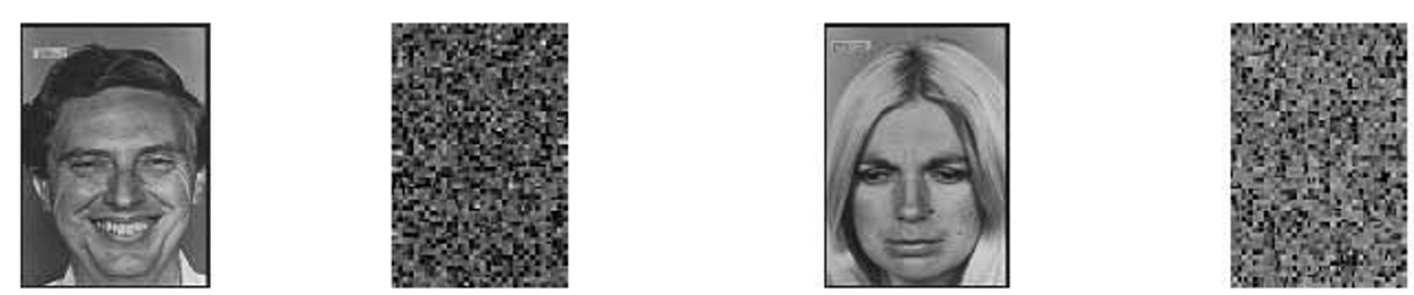

\section{0ms $\quad 11.600 \mathrm{~ms} \quad 400 \mathrm{~ms} \quad 11.600 \mathrm{~ms}$}

\section{Task 1: Recognize Emotion \\ Task 2: Share Emotion \\ Task 3: Detect Earrings (Control)}

Figure I

Schematic illustration of the experimental design. 
scrambled faces were presented for durations between 11 and $12 \mathrm{~s}$ (Figure 1). This long second stimulation period was chosen to provide the subjects sufficient time to engage in appraising the emotional facial expression seen in the first stimulation interval and to allow changs of skin conductance to occur [40]. The faces were presented in random order on a laptop connected to a projector (LCD data projector, VPL-S500E, Sony, Toyko, Japan) on a screen which was placed approximately $50 \mathrm{~cm}$ from the mirror in the head coil. Immediately before each fMRI scan the subjects were instructed to view the faces in a mind set according to one of the following cognitive instructions: a) identify the emotion expressed in the faces (RECOGNIZE), b) empathize with the emotion expressed in the faces (SHARE EMOTION), c) count the earrings in the faces shown (control condition: DETECT EARRINGS). Each instruction was given twice in random order across the subjects, yielding six separate scans per subject. Thus, the visual stimuli were identical in the different experimental conditions, but the visual information to be processed differed according to the instructions. Since each condition was repeated twice, 28 happy, 28 sad and 28 neutral faces were presented. The presentation was done in random order across the subjects to counteract possible sequence or habituation effects. After each condition, the subjects were debriefed about how well they could perform the task.

\section{Functional magnetic resonance imaging}

The subjects lay supine in the MRI scanner and viewed the faces on a screen via a mirror which was fixed to the head coil. Image presentation was controlled by a TTL-stimulus coming from the MRI-scanner as described in detail elsewhere [41]. Scanning was performed on a Siemens Vision $1.5 \mathrm{~T}$ scanner (Erlangen, Germany) using an EPI-GE sequence: $\mathrm{TR}=5 \mathrm{~s}, \mathrm{TE}=66 \mathrm{~ms}$, flip angle $=90^{\circ}$. The whole brain was covered by 30 transaxial slices oriented parallel to the bi-commissural plane with in-plane resolution of $3.125 \times 3.125 \mathrm{~mm}$, slice thickness of $4 \mathrm{~mm}$, and interslice gap of $0.4 \mathrm{~mm}$. Each acquisition consisted of 255 volumes. The first 3 volumes of each session did not enter the analysis. A high-resolution 3D T1-weighted image $(\mathrm{TR}=$ $40 \mathrm{~ms}, \mathrm{TE}=5 \mathrm{~ms}$, flip angle $=40^{\circ}$ ) consisting of $180 \mathrm{sag}$ ittal slices with in plane resolution of $1.0 \times 1.0 \mathrm{~mm}$ was also acquired for each subject.

\section{Data analysis}

Image data were analysed with SPM2 (Wellcome Department of Cognitive Neurology, London, UK; http:// www.fil.ion.ucl.ac.uk/spm). Images were slice-time corrected, realigned, normalized to the template created in the Montreal Neurology Institute (MNI), and spatially smoothed with a $10 \times 10 \times 10 \mathrm{~mm}$ Gaussian filter. The normalization step resampled the images to a voxel size of $2 \times 2 \times 2 \mathrm{~mm}$. The anatomical T1-weighted image of each subject was co-registered to the mean image of the functional images and also normalized to the MNI-space.

For each of the three instruction sets, the happy, sad and neutral face presentations were modelled as well as the corresponding scrambled faces. The models employed the haemodynamic response function provided by SPM2. Data were temporally filtered using a Gaussian low-pass filter of $4 \mathrm{~s}$ and a high-pass filter of $100 \mathrm{~s}$. All data were scaled to the grand mean. Realignment parameters as determined in the realignment step were used as confounding covariates. The duration of all events was modelled with $4 \mathrm{~s}$ for face presentations and $8 \mathrm{~s}$ for the delay period. The repeated condition images of the 18 experimental conditions were averaged for each of the 14 subjects, yielding a total of 252 averaged condition images. Data were modelled using the canonical haemodynamic response function provided by SPM2. The duration of all events was modelled explicitly with $4 \mathrm{~s}$ for face presentations and $8 \mathrm{~s}$ for the delay period. To identify the brain areas related to viewing the faces a comparison with viewing the scrambled faces was calculated. Only areas with a p $<0.05$ corrected at cluster level with a cluster threshold $>20$ voxels were accepted (Table 1 ).

The PCA employed in house software of which some modules were adapted from SPM2. Extracerebral voxels were excluded from the analysis using a mask derived from the gray matter component yielded by segmentation of the high resolution anatomical 3D image volume into gray matter, white matter and cerebrospinal fluid using the segmentation module of SPM2. Voxel values of the segmented image ranged between 0 and 1 ; the mask included only those exceeding 0.35 , excluding most of white matter. Calculation of the residual matrix is the first step. From a matrix whose rows corresponded to the 252 conditons and columns to the 180 thousands voxels in a single image volume the mean voxel value of each row was subtracted from each element as was the mean voxel value of each column subtracted from each element. Thereafter, the grand mean of all voxel values in the original matrix was added to each element. The result of this normalization procedure is the residual matrix for which the row, column and grand means vanish. Using the singular value decomposition implemented in Matlab, the residual matrix was then decomposed into 252 components, consisting of an image, an expression coefficient, and an eigenvalue for each component. The eigenvalue was proportional to the square root of the fraction of variance described by each component, while the expression coefficients described the amount that each subject and condition contributed to the component. The principal components (PCs) were ranked according to the proportion of variance that each component explains, i.e, PC 1 explains the greatest amount of variance. The expression 
Table I: Cerebral activations related to viewing emotional face expressions as compared with viewing scrambled faces

\begin{tabular}{lcccccc}
\hline Anatomical location & \multicolumn{3}{c}{ Coordinates } & Brodmann area & & Cognitive instruction (Task) \\
\hline & $\mathrm{x}$ & $\mathrm{y}$ & $\mathrm{z}$ & & Recognize & Empathize \\
\hline Lingual gyrus R & 28 & -72 & -10 & BA 18 & & + \\
Fusiform gyrus R & 36 & -69 & -10 & BA 19 & + & + \\
Cuneus R & 28 & -78 & 16 & BA 31 & + & + \\
Superior frontal gyrus L & -3 & 22 & 52 & BA 6 & + & + \\
Inferior frontal gyrus L & -49 & 2 & 20 & BA 44 & + & + \\
Inferior frontal gyrus R & 55 & 8 & 16 & BA 44 & + & + \\
Middle frontal gyrus R & 43 & 29 & 30 & BA 9 & + \\
Supramarginal gyrus L & -46 & -49 & 28 & BA 42 & + \\
Parietal operculum R & 50 & -24 & 10 & BA 40 & + \\
Sup. temporal gyrus R & 34 & 16 & -6 & BA 38 & + & + \\
Hypothalamus L & -3 & -6 & -11 & & & + \\
Cerebellum L & -14 & -60 & -22 & & + \\
\hline
\end{tabular}

Activations in categorical analysis with SPM2 at $\mathrm{p}<0.05$ FDR with clusters $>20$ voxels. The coordinates $(x, y, z ; m m)$ of the peak activations $(+)$ are listed in stereotactic space [43]. $L$ refers to left hemisphere; $R$ refers to right hemisphere.

coefficients and voxel values of a PC were orthonormal and their orthogonality reflected the statistical independence of the PCs. The PC image displays the degree to which the voxels covaried in each PC, their voxel values (loadings) ranged between -1 and 1 .

In order to provide a neurophysiological interpretation of the components, statistical tests, e.g. unpaired t-tests and tests of correlation (Pearson) were applied to the expression coefficients. The formal criteria for relevant PCs were: (1) the statistical tests identified the condition differentiating PCs at a significance level of p $<0.001$, and (2) the PCs fulfilled the Guttman-Kaiser criterion, the most common retention criterion in PCA [42] in which PCs associated with eigenvalues of the covariance matrix larger in magnitude than the average of all eigenvalues are retained, implying in this analysis that they ranked among the first 61 PCs. The voxels describing the nodes of a neural network associated with a relevant PC image volume fulfilled the conditions that the voxel values lie in the $1^{\text {st }}$ percentile or the 99th percentile of the volume's voxel value distribution, and that the voxels belong to clusters of greater than 50 voxels.

The anatomical locations of the peak activations and of the coordinates of the maximal PC loadings of the significant PCs are reported in Talairach space [43]. A freely distributed Matlab script [44] effected the transformation from MNI space.

Correlation of the expression coefficients of the significant PCs with the TAS-20, the Beck Depression Inventory, and the SEE scales was conducted using a Pearson twotailed correlation (SPSS for Windows, Version 12.0.1.). The significance level of the correlations was set to $\mathrm{p}<$ 0.01 .

\section{Results}

Before the fMRI experiment the subjects' capacity to experience emotions was tested with the German, 20-item version of the Toronto Alexithymia Scale (TAS-20 [35]). It was found that the 14 participating subjects had a normal mean TAS-20 sum score $(34.1+/-6.3$, range 23$)$. This indicated that each of the subjects had a high capacity of introspection and emotional awareness. In the fMRI session the subjects stated that they could readily identify the seen emotion and generate the corresponding emotion internally as instructed. They detected $92+/-0.2$ percent of the faces wearing earrings.

The categorical analysis showed that viewing the emotional face expressions as compared with viewing the scrambled faces resulted in activations of right visual cortical areas and bilaterally the inferior frontal and superior frontal gyrus (Table 1). Recognizing emotional facial expressions showed the most extensive activation pattern involving also the hypothalamus, the left supramarginal gyrus, cortical areas at the right temporal parietal junction, and the left hypothalamus (Table 1). Empathizing with the seen emotion as compared with object detection (control condition) resulted in one activation area which occurred in the left inferior frontal gyrus. Note, that no activation occurred in the anterior prefrontal or orbitofrontal cortex.

The network analysis revealed that out of the total of 61 retained PCs four differentiated the experimental conditions as found by formal statistical testing (Table 2); for the 11 statistical tests described below, the probability threshold corrected for multiple comparisons is $\mathrm{p}<0.001$. PC1 explained 16.8 percent of the variance and distinguished between viewing the happy, sad and neutral faces from viewing the scrambled faces during RECOGNIZE, 
Table 2: Cerebral circuits in processing of emotional face expressions

\begin{tabular}{|c|c|c|c|c|c|c|}
\hline & \multicolumn{3}{|c|}{ Coordinates } & \multirow[t]{2}{*}{ Anatomical location } & \multirow[t]{2}{*}{ Broadmann area } & \multirow[t]{2}{*}{ Cluster size } \\
\hline & $x$ & $Y$ & Z & & & \\
\hline \multicolumn{7}{|c|}{$\mathrm{PCI}$ : Face identification (16.8\%) } \\
\hline \multirow[t]{6}{*}{ Positive loadings } & 4 & 53 & 4 & Superior frontal gyrus $R$ & BA 10 & 248 \\
\hline & -4 & 48 & -2 & Anterior cingulate $L$ & BA 32 & 81 \\
\hline & 1 & 31 & -7 & Anterior cingulate $R$ & BA 32 & 76 \\
\hline & 38 & 26 & 45 & Middle frontal gyrus $L$ & BA 8 & 66 \\
\hline & -50 & -63 & 31 & Angular gyrus $\mathrm{L}$ & BA 39 & 53 \\
\hline & 44 & -61 & 28 & Supramarginal gyrus $\mathrm{R}$ & BA 39 & 396 \\
\hline \multirow[t]{4}{*}{ Negative loadings } & -21 & -77 & -10 & Lingual gyrus L & BA I8 & 306 \\
\hline & 28 & -72 & -10 & Lingual gyrus $\mathrm{R}$ & BA 18 & 314 \\
\hline & 34 & -70 & 15 & Cuneus R & BA 3I & 428 \\
\hline & -6 & -75 & 44 & Precuneus L & BA 7 & 54 \\
\hline \multicolumn{7}{|c|}{ PC2: Identification of expressed emotion (4.7\%) } \\
\hline \multirow[t]{7}{*}{ Positive loadings } & -30 & -74 & -10 & Fusiform gyrus L & $\mathrm{BA} 19$ & 158 \\
\hline & 36 & -69 & -13 & Fusiform gyrus $\mathrm{R}$ & BA 19 & 252 \\
\hline & 40 & -87 & 8 & Middle occipital gyrus $\mathrm{R}$ & BA 19 & 60 \\
\hline & 6 & 3 & 59 & Superior frontal gyrus $L$ & BA 6 & 87 \\
\hline & -49 & 2 & 20 & Inferior frontal gyrus L & BA 44 & 65 \\
\hline & -3 & -6 & -11 & Hypothalumus L & & 50 \\
\hline & 4 & -6 & -11 & Hypothalumus R & & 63 \\
\hline \multirow[t]{7}{*}{ Negative loadings } & -5 & -73 & 46 & Precuneus L & BA 7 & 51 \\
\hline & 2 & -63 & 52 & Precuneus R & BA 7 & 71 \\
\hline & -63 & -10 & 0 & Superior temporal gyrus $\mathrm{L}$ & BA 22 & 66 \\
\hline & -2 & 4 & 6 & Thalamus $\mathrm{L}$ & & 259 \\
\hline & 7 & -3 & 6 & Thalamus & & 300 \\
\hline & -14 & -30 & -22 & Pons L & & 80 \\
\hline & 50 & -60 & -27 & Neocerebellum $\mathrm{R}$ & & 71 \\
\hline \multicolumn{7}{|c|}{ PC 12: Attention to expressed emotion (1.6\%) } \\
\hline \multirow[t]{6}{*}{ Positive loadings } & 4 & -86 & 17 & Cuneus R & BA 18 & 230 \\
\hline & 54 & 8 & 36 & Middle frontal gyrus $\mathrm{R}$ & BA 9 & 115 \\
\hline & 55 & 17 & 16 & Inferior frontal gyrus R & BA 44 & 56 \\
\hline & -51 & -35 & -2 & Middle temporal gyrus L & BA 22 & 64 \\
\hline & 59 & -56 & 3 & Middle temporal gyrus $\mathrm{R}$ & BA 22 & 119 \\
\hline & 8 & -8 & 12 & Thalamus $\mathrm{R}$ & & 377 \\
\hline \multirow[t]{5}{*}{ Negative loadings } & -12 & -77 & 48 & Precuneus L & BA 7 & 117 \\
\hline & 8 & -69 & 48 & Precuneus $\mathrm{R}$ & BA 7 & 68 \\
\hline & -42 & -48 & 56 & Inferior parietal lobule L & BA 40 & 128 \\
\hline & -32 & 60 & 6 & Middle frontal gyrus $L$ & BA 10 & 246 \\
\hline & 43 & 29 & 30 & Middle frontal gyrus $\mathrm{R}$ & BA 9 & 132 \\
\hline \multicolumn{7}{|c|}{ PC 27: Sense of emotional state (0.9\%) } \\
\hline \multirow[t]{5}{*}{ Positive loadings } & -48 & -57 & -6 & Middle occipital gyrus L & BA 37 & 68 \\
\hline & -28 & 52 & 21 & Middle frontal gyrus L & BA 10 & 153 \\
\hline & -5 & 5 & 0 & Caudate L & & 66 \\
\hline & -13 & -18 & -25 & Pons L & & $|3|$ \\
\hline & -1 & -47 & -36 & Medulla oblongata & & 192 \\
\hline \multirow{6}{*}{ Negative loadings } & -42 & -59 & -17 & Fusiform gyrus L & BA 37 & 58 \\
\hline & -46 & -49 & 28 & Supramarginal gyrus L & BA 42 & 86 \\
\hline & 51 & -34 & 50 & Inferior parietal lobule R & BA 40 & 54 \\
\hline & 55 & -19 & 16 & Parietal operculum R & BA 40 & 53 \\
\hline & -55 & -40 & 8 & Superior temporal gyrus $L$ & BA 22 & 162 \\
\hline & 38 & 8 & -26 & Superior temporal gyrus $\mathrm{R}$ & BA 38 & 59 \\
\hline
\end{tabular}

Shown are the relevant principal components (PC) and their designations. Indicated in the parentheses beside each PC entry is the amount of variance accounted for by that PC. The coordinates $(x, y, z ; \mathrm{mm})$ are listed in stereotactic space [43]. Only those voxels with values lying in the 99 th percentile (positive loadings) or the Ist percentile (negative loadings) and in cluster with sizes greater than 50 voxels were included. $L$ refers to left hemisphere; $\mathrm{R}$ refers to right hemisphere. 
SHARE EMOTION and DETECT EARRINGS. Accordingly, PC1 represented a neural network associated with face identification. The areas with the positive loadings included the right dorsolateral and superior frontal cortex, the left anterior cingulate, and bilaterally the inferior parietal region. The areas with the negative loading included bilaterally the lingual gyrus, the precuneus, and the cuneus, which are areas involved in higher order processing of visual information (Table 2, Figures 2 and 3).

PC2 explained 4.7 percent of the variance and differentiated viewing the happy, sad, and neutral faces from viewing scrambled faces during the RECOGNIZE and SHARE EMOTION conditions (Table 2, Figures 2 and 3). Therefore, PC2 was expected to depict a neural network associated with the identification of an expressed emotion. In fact, the areas with positive loadings included bilaterally the fusiform gyrus, the right middle occipital gyrus, the right superior frontal gyrus, and the left inferior frontal gyrus. The areas with negative loadings included bilaterally the precuneus, the left superior temporal gyrus, as well as the thalamus, pons, and neocerebellum (Table 2). The relative localization of the cortical areas in the occipital cortex and the superior frontal gyrus involved in PC1 and PC2 is illustrated in Figure 3.

PC12 explained 1.6 percent of the variance and reflected the contrast of the conditions SHARE EMOTION and DETECT EARRINGS as well as the contrast of the conditions RECOGNIZE and DETECT EARRINGS during and after viewing happy, sad, or neutral faces. The comparisons showed that PC12 represented a neural network associated with the subjects' attention to an expressed emotion. Areas involved in this network included the right cuneus, bilaterally the precuneus, middle frontal and temporal gyrus, and left inferior parietal lobule (Table 2).

PC27 explained 0.9 percent of the variance and represented the contrast of the conditions SHARE EMOTION with RECOGNIZE during and after viewing happy, sad, and neutral faces. We hypothesized, therefore, that this PC characterizes the neural network subserving the sensation of the emotional state associated with empathy. The regions involved were the left fusiform and middle occipital gyrus, the left middle frontal gyrus, bilaterally the inferior parietal lobule and the superior temporal gyrus (Table 2, Figure 4). Subcortical structures, such as the left caudate and brain stem were also involved.

Correlation of the PC expression coefficients with the behavioral scales of emotional processing yielded the following observations (Table 3). Beck's depression inventory subject scores correlated significantly with the PC2 expression coefficients computed for the RECOGNIZE condition after viewing neutral faces. Since none of the subjects exhibited score values suggestive of depression, this correlation was obtained in the normal range of the Beck's depression inventory. Nevertheless, a more negative emotional experience was related to recognizing neutral faces. Further, the TAS-20 scores correlated negatively with PC2 expression coefficients computed for viewing happy and neutral faces in the control condition DETECT EARRINGS. Note, that the TAS- 20 classified all subjects as highly emotionally sensitive. Thus, this correlation suggests that the more sensitive to processing of emotion our subjects were, the more they were so during implicit processing of faces. The SEE-scale score values related to experience of emotional control correlated negatively with PC 1 expression coefficients computed for viewing of sad faces in the RECOGNIZE condition (Figure 5). A similar correlation was found for PC27 expression coefficients computed for viewing of neutral faces in the RECOGNIZE condition. This suggested that recognizing sad and neutral faces was most pronounced in the subjects whose scores indicated relatively impaired emotional control. Finally, the SEE-scale score values of experience of self-control correlated with PC 12 expression coefficients computed for the SHARE EMOTION condition after viewing happy and neutral faces (Figure 6). This suggested that subjects with a high level of self-control most strongly empathized with happy and neutral faces. Thus, viewing sad faces may have impaired the subject's perception of emotional control, while processing the happy face expression appears to have improved it (Table 3 ). In contrast, the processing of neutral faces was related to a relatively negative emotion, possibly due to the ambiguous character of the neutral faces (Table 3 ).

\section{Discussion}

The novel finding of this event-related fMRI study is that recognizing and empathizing with emotional face expressions engaged a widespread cortical network involving visual areas in the temporal and occipital cortex which are known to be involved in face processing [12,45-62]. Previous fMRI studies have identified several brain regions that are consistently activated when perceiving facial stimuli. These regions include the fusiform gyrus, which is often referred to as the "fusiform face area" [45,49-55,6163], a face-selective region in the occipito-temporal cortex $[45-48,56-60]$, and the superior temporal sulcus $[12,13,48,52]$.

Because the involved cortical areas are active within and across multiple neural networks, the difficulty of assigning a single function to a cortical area becomes apparent [2]. In fact, disagreement over assigning functions to cortical areas does exist, with some arguing that function may be tied to elements of experiment design [64]. However, inability to agree over the specific function of cortical areas would further suggest that a description of "face net- 


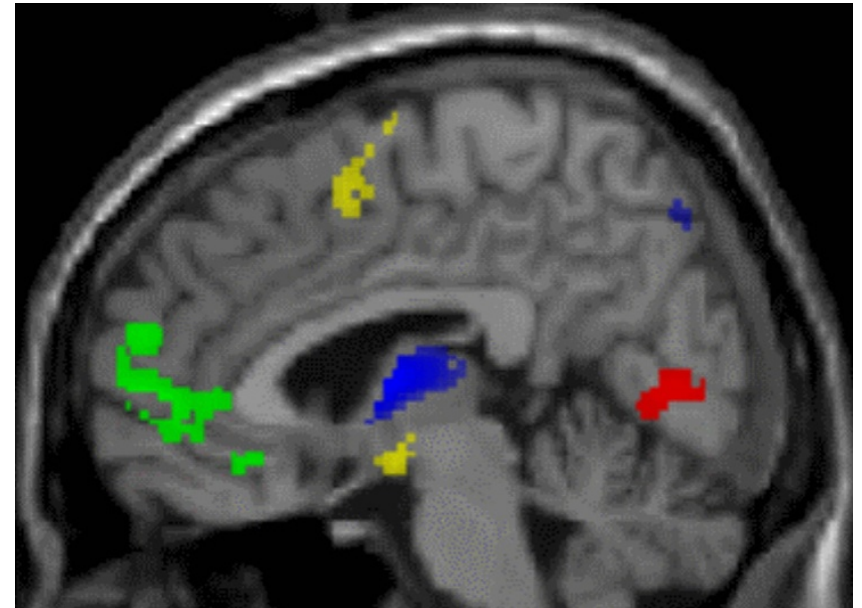

Figure 2

Brain areas involved in the $P C I$ and $P C 2$ superimposed on the canonical single-subject $M R$ image of SPM2 in a sagittal plane showing the areas involved in PCI (cuneus: red - negative loading; anterior portion of superior frontal gyrus: green - positive loading) and in PC2 (precuneus, thalamus: blue negative loading; pre-SMA, hypothalamus: yellow positive expression loading).

work" or "face pathway" may be more accurate than "face region" [65].

Notably, cortical areas in the anterior lateral and medial prefrontal cortex known to participate in manipulating and monitoring information and controlling behavior were also involved [26,66]. Multivariate image analysis using PCA permits the characterization of different networks that include brain areas changing brain activity in related to a given task and brain areas contributing to the function without necessarily changing their activity [28$31,67]$. Specifically, we applied inferential statistical tests to identify the PCs that effectively differentiated between the experimental conditions $[31,68]$. The four thereby identified PCs showed more cerebral areas involved than in the simple task comparions. These PCs revealed correlations with behavioral data obtained prior to the fMRI acquisitions, which highlighted their functional relevance.

\section{Functional neural networks}

Of the four differentiating PCs, PC1 distingished the neural network involved in face indentification, since the involved lingual gyrus, cuneus and precuneus have been known to be involved in face recognition and visual processing $[68,69]$. The lingual gyrus has been linked to an early stage of facial processing which occurs before specific identification occurs [70]. Conversely, the angular gyrus and the anterior cingulate have been shown previ-

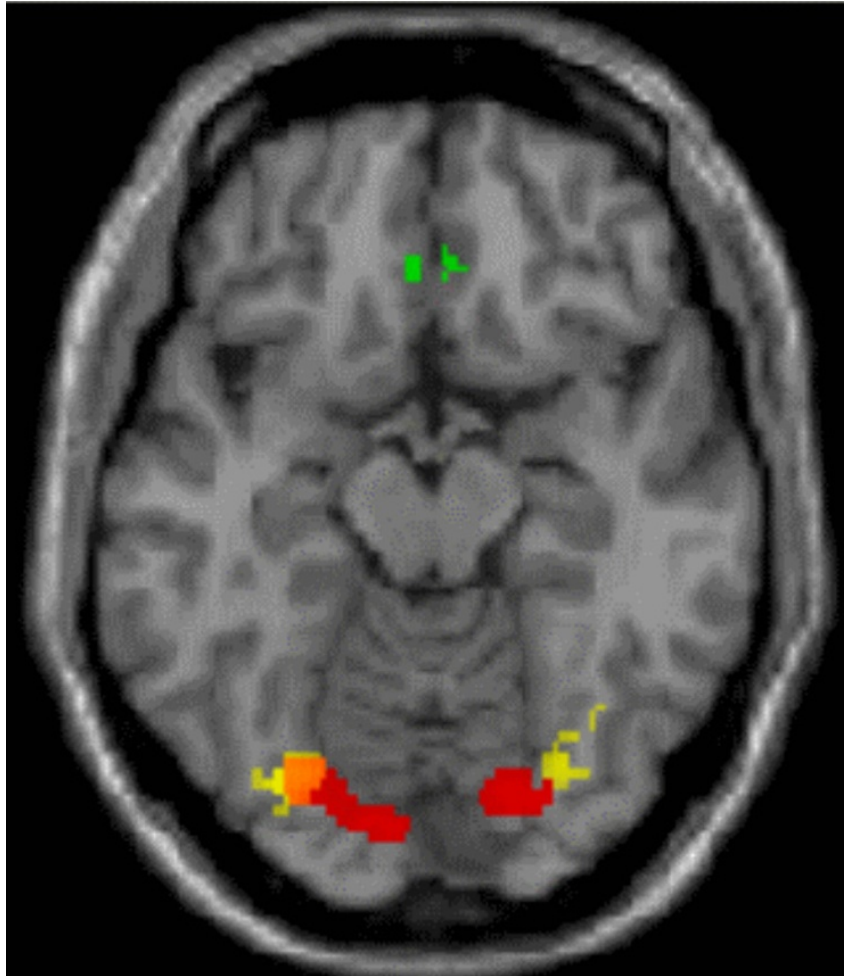

Figure 3

Brain areas involved in PCI and PC2 superimposed on the canonical single-subject MR image of SPM2 in an axial plane showing the lateral position of activity in the fusiform face area (PC2, yellow, positive loading) relative to $\mathrm{PCI}$ (red, negative loading). Note the medial prefrontal involvement in PCI (green, positive loading).

ously to be involved in attention [71], and the anterior portion of the superior frontal gyrus has been implicated in theory of mind paradigms $[26,71]$.

PC2 represented the functional neural network associated with detecting emotional facial expressions, since the network nodes included bilaterally the fusiform gyrus, corresponding to the so-called fusiform face area. Some studies have suggested that the fusiform face area mediates the lower order processing of simple face recognition [72], while others have implicated it in higher order processing of faces at a specific level [45] including emotional detection [73] and identity discrimination [58,64]. Also included among the nodes were the posterior portion of the superior frontal and the inferior frontal gyrus, which have been implicated in higher order processing of faces involving the perception of gaze direction [74], attention to faces [75], eye and mouth movements [56], and empathy $[25,76]$. Thus, our analysis, relating the concerted action of the fusiform and superior frontal gyrus to the detection of emotional face expressions, substantiates pre- 


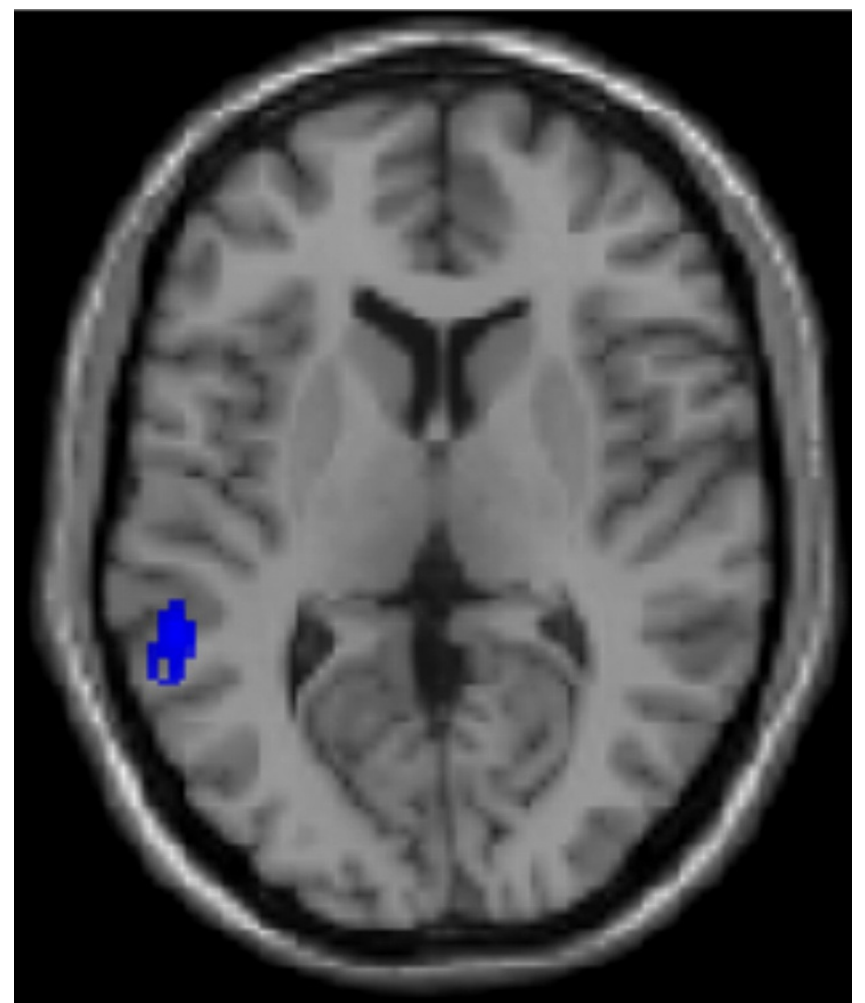

Figure 4

Involvement of the left superior temporal gyrus in PC27 superimposed on the canonical single-subject MR image of SPM2 in an axial plane (blue, negative loading).

vious work showing that the conjoint activity of the fusiform gyrus and cortex lining the superior temporal sulcus are related to higher order processing of facial features $[45,53,56,58,64,72-74]$. We propose that these areas constitute a system involved in facial affect processing.

PC2 also implicated subcortical structures such as the thalamus and the hypothalamus bilaterally, and the cerebellum. These structures belong to the anterior cingulate ventral striatum - thalamus - hypothalamus loop [76-78] and are thought to regulate the emotions, drives, and motivated behavior $[2,79,80]$.

The third statistically relevant PC, PC12, was related to the attentive processing of expressed emotions. Accordingly, the involved cortical areas, e.g. the precuneus, cuneus, middle frontal gyrus, and thalamus have all been linked to tasks related to controlling attention [81-83]. The inferior frontal gyrus has been shown to be involved in response inhibition during attention [84], while the middle temporal gyrus has been implicated in attention to facial stimuli [47] and to visual attention in general $[81,82]$.

PC27 appeared to represent a network mediating a 'feeling' or sense of an observed emotional state. In fact, the superior temporal gyrus has been shown to play an important role in perceiving self/other distinctions, and, importantly, in experiencing a sense of agency $[85,86]$. Also, the superior temporal gyrus seems to be important for "theory of mind" capabilities [87-89]. Similarly, the right inferior parietal lobule has been related to an experienced sense of agency $[85,86]$, while the temporal parietal junction has been thought to be crucial to larger networks mediating spatial unity of the self and body [89,90], and attention $[81,91,92]$.

\section{Activity within and across functional networks}

Empathic processes allow individuals to quickly asses the emotional states and needs of other individuals while rapidly transmitting our own experiences and needs [93]. Thus, emphatic experiences are crucial to rapid and successful social interaction $[94,95]$. The recognition of emotional states and cognitive processing of another's emotional expression are critical skillsets utilized by all humans upon perceiving another person's face. In order to properly behave in a social situation, one must understand the context of the situation before an appropriate action can be taken.

The participation of the prefrontal cortex in the four relevant PCs in our study not only support the view that dif-

Table 3: Correlation of behavioral data vs. expression coefficients

\begin{tabular}{|c|c|c|c|c|c|c|c|}
\hline \multicolumn{2}{|c|}{ Toronto alexthymia scale-20 } & \multicolumn{2}{|c|}{ Beck depression inventory } & \multicolumn{2}{|c|}{ Experience of control of emotion } & \multicolumn{2}{|c|}{ Experience of self control } \\
\hline $\mathrm{R}$ value & $P$ value & $\mathrm{R}$ value & $P$ value & $\mathrm{R}$ value & $P$ value & $\mathrm{R}$ value & $P$ value \\
\hline \multicolumn{2}{|c|}{ Condition/PC } & \multicolumn{2}{|c|}{ Condition/PC } & \multicolumn{2}{|c|}{ Condition/PC } & \multicolumn{2}{|c|}{ Condition/PC } \\
\hline $\mathrm{CH} 2-0.670$ & 0.009 & $\operatorname{RaN} 20.667$ & 0.009 & $R S$ I -0.687 & 0.007 & $\mathrm{EaH} / 20.757$ & 0.002 \\
\hline CN $2-0.683$ & 0.007 & & & RN $27-0.675$ & 0.008 & $\operatorname{EaN} / 20.778$ & 0.001 \\
\hline
\end{tabular}

$\mathrm{C}=$ DETECT EARRINGS (Control), $\mathrm{E}=\mathrm{SHARE}$ EMOTION, $\mathrm{R}=\mathrm{RECOGNIZE}, \mathrm{H}=$ Happy, $\mathrm{S}=\mathrm{Sad}, \mathrm{N}=\mathrm{Neutral}$, aH $=$ after Happy, aN $=$ after Neutral 


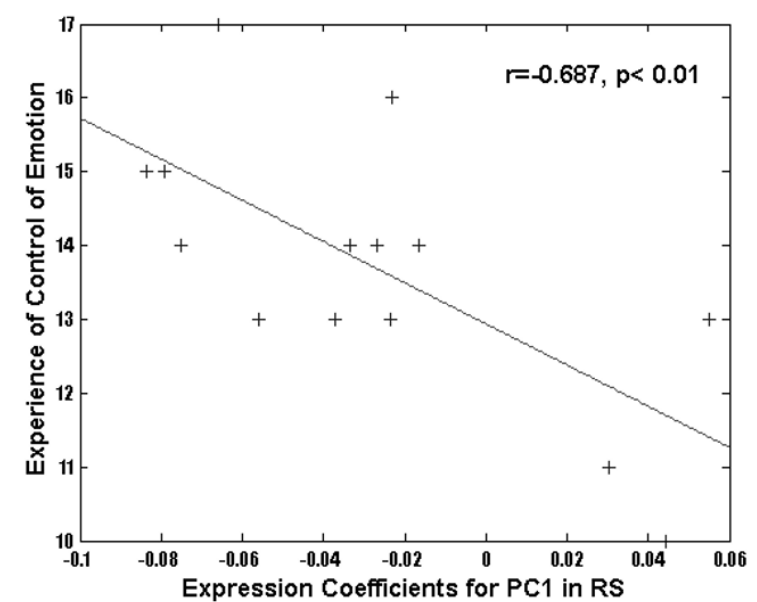

Figure 5

Regression plots of expression coefficients of PCI with data of the test scores of the 14 subjects highlighting the functional relevance of these PCs.

ferent cognitive functions work together to play a role in distinct neural networks, but, as well, further the notion that the medial pre-frontal cortex is the junction point where different visual, attentive, emotional and higher order cognitive processes come together in order to allow for a subjective reaction towards the exterior world [26]. The medial-pre-frontal integration of own cognitive concepts, implicit affective schemata and empathy-based anticipation of the possible reactions of important other individuals allows for an effective selection and adaptive planning of one's own actions. The face as the most signif-

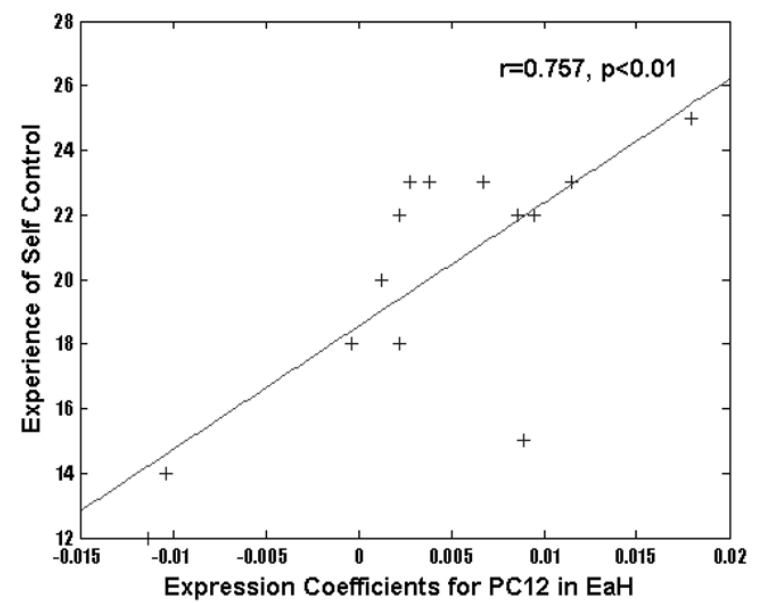

Figure 6

Regression plots of expression coefficients of PCI 2 with data of the test scores of the I 4 subjects highlighting the functional relevance of these PCs. icant carrier of emotional information is an important source for these evaluative and appraisal functions.

The four neural networks involved in the recognition of faces and the cognitive control of emotions capture the functions that this study aimed to explore. Our results support numerous studies that hypothesize distinct neural networks for recognizing facial features and emotional expressions [11,13-17,96,97]. In particular, although PC 1 and PC 2 differentiated lower-order facial identification and higher-order facial feature processing, the cortical areas within each PC contained brain areas associated with functions effected by the neural networks depicted in the other PCs. Thus, the middle frontal gyrus activated in all four principal components has been shown to be related to inhibition [98], successful recognition of previously studied items [99], and successful error detection, response inhibition, interference resolution, and behavioral conflict resolution associated with completing the Stroop Color-Word task [100]. Moreover, the PC representing a basic visual function, PC1 included activation of the right anterior cingulate which has been shown to severely impact the processing of emotional expressions $[101,102]$. Apparent also in PC1, the lingual gyrus and cuneus have been implicated in the higher-order processing of emotional expression [103] and the lingual gyrus has been implicated in motional information [104]. Interestingly the anterior cingulate has also been thought to cognitively monitor the control of response conflict in information processing [105] and in the regulation of cognitive and emotional processing [106]. In a case study, Steeves et al. [61] demonstrated that an intact fusiform face area was sufficient for identifying faces, but a lesion in the occipital face area prevented the patient from higher-order processing of faces such as identity, gender, or emotion.

Out results are also in accordance with the idea that emotion recognition may play a role in the lower order process of face identification, but this role is limited at best and functions mainly as a stepping stone for higher order recognition of emotional expressions. [107]. Although the lingual gyrus in PC1 and the fusiform face area in PC2 are located closely anatomically, our analysis suggests that they are involved in distinct neural networks related to different subfunctions, face identification and detection of emotional facial expressions, repectively, of facial processing. Nevertheless, it is possible that the subjects recognized the emotions implicitly also in the DETECT EARRING condition. However, the cognitive instruction in this study was that during the RECOGNIZE and SHARE EMOTION conditions the subjects had to appraise the emotions explicitly. In fact, this difference resulted in additional brain structures involved in the explicit processing conditions. 
The involvement of closely adjacent cortical areas in different subfunctions related to the detection of emotional face expressions highlights the difficulty of assigning exclusive functional relevance to a particular area and suggests the multi-functional nature of brain areas which participate in multiple, interconnected neural networks performing lower-order as well as higher-order neural processing.

\section{Conclusion}

Implemented in this study using PCA, employment of a network analysis helps to elucidate the coordination of multiple cortical areas in brain functions. We are able to identify the participation of multiple neural networks in processing highly differentiated cognitive aspects of emotion. Ultimately, placing cortical areas within the context of a particular neural network may be the key to defining the functional relevance of individual cortical areas. This more sensitive approach gives us a better picture of the constituent components involved in the processes of recognizing and empathizing with emotional facial expressions by discerning networks of activity, rather than simply defining areas of activity $[28,29]$. This in turn gives us a better idea of how the functional connectivity of constituent regions work together in order to allow a person to recognize and process the facial expressions of another.

\section{Competing interests}

The authors declare that they have no competing interests.

\section{Authors' contributions}

JSN performed the statistical analysis and drafted the manuscript. DS participated in the design of the study, programmed the stimuli and performed the acquisition of the fMRI data. SF participated in the fMRI experiment and the statistical analysis. RS participated in the design of the study and performed the psychological investigations. MF participated in the design of the study and contributed to the interpretation of the data and drafting of the manuscript. HJW participated in the design of the study and participated in the acquisition of the fMRI data. NPA contributed to the design of the study and participated in the interpretation of the data and drafting of the manuscript. JM performed the statistical analysis and participated in the interpretation of the data. RJS participated in the design of the study, contributed to the statistical analysis, the data interpretation, and drafting the manuscript. All authors read and approved the final manuscript.

\section{Acknowledgements}

The authors thank E. Rädisch for expert technical assistance during the fMRI experiment.

\section{References}

I. Leppanen JM, Moulson MC, Vogel-Farley VK, Nelson CA: An ERP study of emotional face processing in the adult and infant brain. Child Develop 2007, 78:232-245.

2. Adolphs R: Neural systems for recognizing emotion. Curr Opin Neurobiol 2002, I 2:169-I77.

3. Williams KR, Wishart JG, Pitcairn TK, Willis DS: Emotion recognition by children with Down syndrome: Investigation of specific impairments and error patterns. Am J Ment Retard 2005, I I 0:378-392.

4. Blair RJR: Facial expressions, their communicatory functions and neuro-cognitive substrates. Phil Trans R Soc Lond 2003, 358:56I-572.

5. Eimer $M$, Homes A: An ERP study on the time course of emotional face processing. NeuroReport 2002, I 3: I-5.

6. Ruby R, Decety J: What you believe versus what you think they believe: a neuroimaging study of conceptual perspective-taking. Eur J Neurosci 2003, I 7:2475-2480.

7. Fonagy P, Gergely G, Jurist EL: Affect Regulation, Mentalization, and the Development of the Self. John Wiley \& Sons. New York; 2005.

8. Decety J, Lamm C: Human empathy through the lens of social neuroscience. ScientificWorldJournal 2006, 6: I I46-I I 63.

9. Preston SD, de Waal FBM: Empathy: its ultimate and proximate bases. Behav Brain Sci 2002, 25: I-72.

10. lacoboni M, Molnar-Szakacs I, Gallese V, Buccino G, Mazziotta JC, Rizzolatti G: Grasping the intentions of others with one's own mirror neuron system. PLoS Biology 2005, 3:e79. 0529-0535

II. Jackson PL, Brunet E, Meltzoff AN, Decety J: Empathy examined through the neural mechanisms involved in imagining how I feel versus how you feel pain. Neuropsychologia 2005, 44:752-76I.

12. Calder AJ, Young AW: Understanding the recognition of facial identitiy and facial expression. Nat Neurosci 2005, 6:64I-65I.

13. Haxby JV, Gobbini MI, Furey ML, Ishai A, Schouten JL, Pietrini P: Distributed and overlapping representations of faces and objects in ventral temporal cortex. Science 200I, 293:2425-2430.

14. Posamentier MT, Abdi H: Processing faces and facial expressions. Neuropsychol Rev 2003, I3: I |3- I43.

15. Sinha $P$, Balas B, Ostrovsky $Y$, Russell R: Face recognition by humans: Nineteen results all computer vision researchers should know about. IEEE 2006, 94: I948-1962.

16. Crocker $V$, McDonald S: Recognition of emotion from facial expression following traumatic brain injury. Brain Inj 2005, 19:787-799.

17. Ashley V, Vuilleumier P, Swick D: Time course and specificity of event-related poetentials to emotional expressions. Neuroreport 2003, 15:21 1-216.

18. Blau VC, Maurer U, Tottenham N, McCandliss BD: The face-specific NI70 component is modulated by emotional facial expression. Behav Brain Funct 2007, 3:7.

19. Liu J, Harris A, Kanwisher N: Stages of processing in face perception: an MEG study. Neuroscience 2002, 5:910-916.

20. Kaufmann J, Schweinberger SR: Expression influences the recognition of familiar faces. Perception 2004, 33:399-408.

21. Gallese V, Keysers C, Rizzolatti G: A unifying view of the basis of social cognition. Trends Cogn Sci 2004, 8(9):396-403.

22. Uddin LQ, Molnar-Szakacs I, Zaidel E, lacoboni M: fTMS to the right inferior parietal lobule disrupts self-other discrimination. Soc Cogn Affect Neurosci 2007, I:65-7I.

23. Schütz-Bosbach S, Mancini B, Aglioti SM, Haggard P: Self and other in the human motor system. Curr Biol 2006, 16:1830-1834.

24. Decety J, Grezes J: The power of simulation: Imagining one's own and other's behavior. Brain Res 2006, I 2:4-14.

25. Seitz RJ, Nickel J, Azari NP: Functional modularity of the medial prefrontal cortex: involvement in human empathy. Neuropsychology 2006, 20:743-75I.

26. Decety J, Jackson PL: The functional architecture of Human Empathy. Behav Cogn Neurosci Rev 2004, 3:7I- 100.

27. Horwitz B: Data analysis paradigms for metabolic-flow data: Combining neural modeling and functional neuroimaging. Human Brain Mapp 1994, 2: I I2-I 22.

28. Alexander GE, Moeller JR: Application of the subprofile model to functional imaging in neuropsychiatric disorders: A principal component approach to modeling brain function in disease. Human Brain Mapp 1994, 2:79-94. 
29. Friston KJ, Holmes AP, Worsely KJ, Poline J-P, Frith CD, Frackowiak RSJ: Statistical parametric maps in functional imaging: A generalized linear approach. Human Brain Mapp 1994, 2:189-210.

30. Mclntosh AR: Towards a network theory of cognition. Neural Netw 2000, I 3:861-870.

31. Seitz RJ, Knorr U, Azari NP, Weder B: Cerebral networks in sensorimotor distrubances. Brain Res Bull 200I, 54:299-305.

32. Oldfield RC: The assessment and analysis of handedness: the Edinburgh inventory. Neuropsychologia 1971, 9:97-I I3.

33. Bagby RM, Parker JDA, Taylor GJ: The Twenty-Item Toronto Alexithymia Scale-I. Item selection and cross-validation of the factor structure. I Psychosomat Res 1994, 38:23-32.

34. Bagby RM, Taylor GJ, Parker JDA: The Twenty-Item Toronto Alexithymia Scale-II. Convergent, Discriminant, and Concurrent Validity. J Psychosomat Res 1994, 38:33-40.

35. Franz M, Popp K, Schaefer R, Sitte W, Schneider C, Hardt J, Decker $\mathrm{O}$, Braehler E: Alexithymia in the German general population. Soc Psychiatry Psych Epidemiol 2008, 43:54-62.

36. Hautzinger M, Bailer M, Worall H, Keller F: BDI. Beck-Depres sions-Inventar. In Huber Bern Göttingen Toronto Seattle; 1995.

37. Behr M, Becker M: SEE. Skalen zum Erleben von Emotionen. In Manual Göttingen: Hogrefe; 2004.

38. Ekman P, Friesen WV: Pictures of Facial Affect [slides]. Palo Alto, CA: Consulting Psychologists Press; 1996.

39. Esslen M, Pascual-Marqui RD, Hell D, Kochi K, Lehmann D: Brain areas and time course of emotional processing. Neuroimage 2004, 2 I: I I 89-203.

40. Franz M, Schaefer R, Schneider C, Sitte W, Bachor J: Visual eventrelated potentials in subjects with alexithymia: modified processing of emotional aversive information. Am J Psychiat 2004, I 6 I:728-735.

4I. Kleiser R, Wittsack H-J, Bütefisch CM, Jörgens S, Seitz RJ: Functional activation within the PI-DWI mismatch region in recovery from hemiparetic stroke: preliminary observations. Neuroimage 2005, 24:515-523.

42. Jackson J: A User's Guide to Principal Components. John Wiley \& Sons: New York; |991.

43. Talairach J, Tournoux P: Co-planar stereotaxic atlas of the human brain. New York: Thieme; 1998

44. Brett M: The MNI brain and the Talairach atlas. 14-2-2002. Ref Type: Internet Communication .

45. Gauthier: The fusiform 'face area' is part of a network that processes faces at the individual level. J Cogn Neurosci 2000, I 2:495-504.

46. George N, Dolan RJ, Fink GR, Baylis GC, Russell C, Driver J: Contrast polarity and face recognition in the human fusiform gyrus. Nat Neuroscience 1999, 2:574-580.

47. Hadjikhani N, Gelder B: Neural basis of prosopagnosia. Human Brain Mapp 2002, 16:176-182.

48. Halgren E, Dale AM, Sereno MI, Tootell R, Marinkovic K, Rosen BR: Location of human face-selective cortex with respect to retinotopic areas. Human Brain Mapp 1999, 7:29-37.

49. Ishai A, Ungerleider LG, Haxby JV: Distributed neural systems for the generation of visual images. Neuron 2000, 28:979-990.

50. Kanwisher N, McDermott J, Chun MM: The fusiform face area: A module in human extrastriate cortex specialized for face perception. J Neurosci 1997, I 7:4302-43 I I.

51. Lerner Y, Hendler T, Ben-Bashat D, Harel M, Malach R: A hierarchical axis of object processing stages in the human visual cor tex. Cereb Cortex 200 I, I I:287-297.

52. Nakamura K, Kawashima R, Sato N, Nakamura , Sugiura M, Kato T, Hatano K, Ito K, Fukuda H, Schormann T, Zilles K: Functional delineation of the human occipitoltemporal areas related to face and scene processing; a PET study. Brain 2000 123:1903-1912

53. Narumoto J, Okada T, Sadato N, Fukui K, Yonekura Y: Attention to emotion modulates $\mathrm{fMRI}$ activity in human right superior temporal sulcus. Cogn Brain Res 200I, I 2(2):225-23I.

54. Onitsuka T, Shenton ME, Kasai K, Nestor PG, Toner SK, Kikinis R, Jolesz FA: Fusiform gyrus volume reduction and facial recognition in chronic schizophrenia. Arch Gen Psychiatry 2003, 60(4):349-355.

55. Pizzagalli DA, Lehmann D, Hendrick AM, Regard M, Pascual-Marqui RD, Davidson RJ: Affective judgments of faces modulate early activity ( $160 \mathrm{~ms})$ within the fusiform gyri. Neuroimage 2002 , 16:663-677.
56. Puce A, Allison T, Asgari M, Gore JC, McCarthy G: Differential sensitivity of human visual cortex to faces, letterstrings, and textures: A functional magnetic resonance imaging study. J Neurosci 1996, 1 6:5205-5215.

57. Rossion B, Caldara R, Seghier M, Schuller A-M, Lazeyras F, Mayer E: A network of occipito-temporal face-sensitive areas besides the right middle fusiform gyrus is necessary for normal face processing. Brain 2003, I 26:2381-2395.

58. Rotshtein P, Henson RNA, Treves A, Driver J, Dolan RJ: Morphing Marilyn into Maggie dissociates physical and identity face representations in the brain. Nat Neuroscience 2005, 8:107-II3.

59. Schiltz C, Sorger B, Caldara R, Ahmed F, Mayer E, Goebel R, Rossion $B$ : Impaired face discrimination in acquired prosopagnosia is associated with abnormal response to individual faces in the right middle fusiform gyrus. Cereb Cortex 2006, I 6(4):574-586.

60. Sergent J, Ohta S, MacDonald B: Functional neuroanatomy of face and object processing. Brain 1992, I I 5: I 5-36.

6I. Steeves JK, Culham JC, Duchaine BC, Pratesi CC, Valyear KF, Schindler I, Humphrey GK, Milner AD, Goodale MA: The fusiform face area is not sufficient for face recognition: Evidence from a patient with dense prosopagnosia and no occipital face area. Neuropsychologia 2006, 44:594-609.

62. Yovel G, Kanwisher N: The neural basis of the behavioral faceinversion effect. Curr Biol 2005, I 5:2256-2262.

63. Allison T, Giner H, McCarthy G, Nore AC, Puce A, Luby M, Spencer DD: Face recognition in human extrastriate cortex. I Neurophysiol 1994, 7 I:82 I-825.

64. Winston JS, Henson RNA, Fine-Goulden MR, Dolan RJ: fMRI-adaptation reveals dissociable neural representations of identity and expression in face perception. I Neurophysiol 2004, 92:1830-1839.

65. Takamura M: Prosopagnosia: A look at the laterality and specificity issues using evidence from neuropsychology and neurophysiology. The Harvard Brain 1996, Spring:9-I3.

66. Ramnani N, Owen AM: Anterior prefrontal cortex: Insights into function from anatomy and neuroimaging. Nat Rev Neurosci 2004, 3:184-194.

67. Sugiura M, Friston KJ, Willmes K, Shah NJ, Zilles K, Fink GR: Analysis of intersubject variability in activation: an application to the incidental episodic retrieval during recognition test. Human Brain Mapp 2007, 28:49-58

68. Azari NP, Missimer J, Seitz RJ: Religious experience and emotion: Evidence for distinctive neural patterns. Int J Psychol Religion 2005, | 5:263-28|

69. Mobbs D, Garrett AS, Menon V, Rose FE, Bellugi U, Reiss AL: Anomalous brain activation during face and gaze processing in Williams syndrome. Neurology 2004, 62:2070-2076.

70. Luks TL, Simpson GV: Preparatory deployment of attention to motion activates higher-order motion-processing brain regions. Neuroimage 2004, 22:1515-1522.

7I. Gilbert SJ, Spengler S, Simons JS, Steele JD, Lawrie SM, Frith CD, Burgess PW: Functional specialization within rostral prefrontal cortex (area I0): a meta-analysis. J Cogn Neurosci 2006, I 8:932-948.

72. Kanwisher N, Tong $\mathrm{F}$, Nakayama $\mathrm{K}$ : The effect of face inversion on the human fusiform face area. Cognition 1998, 68: I- II.

73. Dolan RJ, Fletcher P, Morris J, Kapur N, Deakin JF, Frith CD: Neural activation during covert processing of positive emotional facial expressions. Neuroimage 1996, 4:194-200.

74. Hoffman EA, Haxby JV: Distinct representations of eye gaze and identity in the distributed human neural system for face perception. Nat Neurosci 2000, 3:80-84.

75. Pessoa L, McKenna E, Gutierrez E, Ungerleider LG: Neural processing of emotional faces requires attention. Proc Natl Acad Sci 2002, 99: I | 458- I | 463 .

76. Nakamura K, Kawashima R, Ito K, Sugiura M, Kato T, Nakamura A, Hatano K, Nagumo S, Kubota K, Fukuda H, Kojima S: Activation of the right inferior frontal cortex during assessment of facial emotion. J Neurophysiol 1999, 82:1610-1614.

77. Powell EW, Leman RB: Connections of the nucelus accumbens. Brain Res 1976, 1 05:389-403.

78. Roberts AC, Tomic DL, Parkinson CH, Roeling TA, Cutter D, Robbins TW, Everitt BJ: Forebrain connectivity of the prefrontal cortex in the marmoset monkey (Callithrix jacchus): an anterograde and retrograde tract-tracing study. I Comp Neurol 2007, 502:86-I I 2. 
79. Tekin S, Cummings JL: Frontal-subcortical neuronal circuits and clinical neuropsychiatry: An update. J Psychosomat Res 2002, 53:647-654.

80. Siffert J, Allen JC: Late effects of therapy of thalamic and hypothalamic tumors in childhood: Vascular, neurobehavioral and neoplastic. Pediatr Neurosurg 2000, 33: I05- I I I.

8I. Corbetta M, Kincade JM, Ollinger JM, McAvoy MP, Shulman GL: Voluntary orienting is dissociated from target detection in human posterior parietal cortex. Neuroscience 2000, 3:292-297.

82. Corbetta M, Shulman GL: Human cortical mechanisms of visual attention during orienting and search. Phil Trans $R$ Soc Lond 1998, 353:1353-1362

83. Hariri AR, Bookheimer SY, Mazziotta JC: Modulatory emotional responses: effect of a neurocortical network on the limbic system. Neuroreport 2000, I I:43-48.

84. Tamm L, Menon V, Reiss A: Parietal attentional system aberrations during target detection in adolescents with attention deficit hyperactivity disorder: Event-related fMRI evidence. Am J Psych 2006, I63:1033-1043.

85. Garavan H, Ross TJ, Stein EA: Right hemispheric dominance of inhibitory control: an event-related functional MRI study. Proc Natl Acad Sci USA 1999, 96:8301-8306.

86. Decety J, Chaminade T, Grezes J, Meltzoff AN: A PET exploration of the neural mechanisms involved in reciprocal imitation. Neuroimage 200I, I 5:265-272.

87. Frith U, Frith CD: Development and neurophysiology of mentalizing. Phil Trans R Soc Lond 2003, 358:459-473.

88. Farrer C, Franck N, Georgieff N, Frith CD, Decety J, Jeannerod M: Modulating the experience of agency: a positron emission tomography study. Neuroimage 2003, I 8:324-333.

89. Völlm BA, Taylor AN, Richardson P, Corcoran R, Stirling J, McKie S, Deakin JF, Elliot R: Neuronal correlates of theory of mind and empathy: A functional magnetic resonance imaging study in a nonverbal task. Neuroimage 2005, 29:90-98.

90. Blanke O, Mohr C, Michel CM, Pascual-Leone A, Brugger P, Seeck M, Landis T, Thut G: Linking out-of-body experience and self processing to mental own-body-imagery at the temporoparietal junction. I Neurosci 2005, 25:550-557.

91. Karnath H, Himmelbach M, Rorden $\mathrm{C}$ : The subcortical anatomy of human spatial neglect: putamen, caudate nucleus and pulvinar. Brain 2002, I 25:350-360.

92. Hedden T, Gabrieli JDE: The ebb and flow of attention in the human brain. Nat Neurosci 2006, 9:863-865.

93. Saxe R, Kanwisher N: People thinking about thinking people: The role of the temporo-parietal junction in "theory of mind". Neuroimage 2003, I9:1835-1842.

94. Carr L, lacoboni M, Dubeau M-C, Mazziota JC, Lenzi GL: Neural mechanisms of empathy in humans: A relay from neural systems for imitation to limbic areas. Proc Natl Acad Sci USA 2003, 1 00:5497-5592.

95. Singer T, Seymour B, O'Doherty J, Kaube H, Dolan RJ, Frith CD: Empathy for pain involves the affective but not sensory components of pain. Science 2004, 303(566 I): I I57-I I62.

96. Haxby JV, Hoffman EA, Gobbini MI: The distributed human neural system for face perception. TICS 2000, 4:223-233.

97. Schweinsburg AD, Paulus MP, Barlett VC, Killeen LA, Caldwell LC, Pulido C, Brown SA, Tapert SR: An fMRI study of response inhibition in youths with a family history of alcoholism. Ann NY Acad Sci 2004, 1021:391-394.

98. lidaka T, Matsumoto A, Nogawa J, Yamamoto Y, Sadato N: Frontoparietal network involved in successful retrieval from episodic memory. Spatial and temporal analyses using $\mathrm{MMRI}$ and ERP. Cereb Cortex 2006, I 6: I349-1360.

99. Mclntosh AR, Rajah MN, Lobaugh N: Interactions of prefrontal cortex in relation to awareness in sensory learning. Science 1999, 284: $153 \mid-1533$.

100. Adleman NE, Menon V, Blasey CM, White CD, Warsofsky IS, Glover $\mathrm{GH}$, Reiss AL: A developmental fMRI study of the stroop colorword task. Neuroimage 2002, 16:61-75.

101. Lane RD, Rieman EM, Axelrod B, Yun LS, Holmes A, Schwartz GE: Neural correlates of levels of emotional awareness. Evidence of an interaction between emotion and attention in the anterior cingulate cortex. J Cogn Neurosci 1998, I 0:525-535.

102. Schäfer R, Popp K, Jörgens S, Lindenberg R, Franz M, Seitz RJ: Alexithymia-like disorder in right anterior cingulate infarction. Neurocase 2007, I 3:201-208.
103. Fu CHY, Williams SCR, Brammer MJ, Suckling J, Kim J, Cleare AJ, Walsh ND, Mitterschiffthaler MT, Andrew CM, Pich EM, Bullmore ET: Neural resonses to happy facial expressions in major depression following antidepressant treatment. Am J Psych 2006, I 64:599-607.

104. Servos P, Osu R, Santi A, Kawato M: The neural substrates of biological motion perception: An fMRI study. Cereb Cortex 2002, 1 2:772-782

105. Barch DM, Braver TS, Akbudak E, Conturo' T, Ollinger J, Snyder A: Anterior cingulate cortex and response conflict: Effects of response modality and processing domain. Cereb Cortex 200I, I I:837-848.

106. Bush G, Luu P, Posner MI: Cognitive and emotional influences in anterior cingulate cortex. Trends Cogn Sci 2000, 4(6):2 I 5-222.

107. Fichtenholtz HM, Dean HL, Dillon DG, Yamasaki H, McCarthy G, LaBar KS: Emotion-attention network interactions during a visual oddball task. Cogn Brain Res 2004, 20:67-80.

Publish with Bio Med Central and every scientist can read your work free of charge

"BioMed Central will be the most significant development for disseminating the results of biomedical research in our lifetime. "

Sir Paul Nurse, Cancer Research UK

Your research papers will be:

- available free of charge to the entire biomedical community

- peer reviewed and published immediately upon acceptance

- cited in PubMed and archived on PubMed Central

- yours - you keep the copyright 